\title{
Switch-Peptides as Folding Precursors in Self-Assembling Peptides and Amyloid Fibrillogenesis
}

Gabriele Tuchscherer ${ }^{1}$, Arunan Chandravarkar ${ }^{1}$, Marie-Stéphanie Camus $^{1}$, Jérémy Bérard ${ }^{1}$, Karine Murat ${ }^{1}$, Adrian Schmid ${ }^{2}$, Richard Mimna ${ }^{1}$, Hilal A. Lashuel ${ }^{2}$, Manfred Mutter ${ }^{1}$

${ }^{1}$ Institute of Chemical Sciences and Engineering, Ecole Polytechnique Fédérale de Lausanne, EPFL, CH-1015 Lausanne, Switzerland

${ }^{2}$ Brain Mind Institute, Ecole Polytechnique Fédérale de Lausanne, EPFL, CH-1015 Lausanne, Switzerland

Received 14 November 2006; revised 19 December 2006; accepted 20 December 2006

Published online 5 January 2007 in Wiley InterScience (www.interscience.wiley.com). DOI 10.1002/bip.20663

\section{ABSTRACT:}

The study of conformational transitions of peptides has obtained considerable attention recently because of their importance as a molecular key event in a variety of degenerative diseases. However, the study of peptide selfassembly into $\beta$-sheets and amyloid $\beta$ (A $\beta$ ) fibrils is strongly hampered by their difficult synthetic access and low solubility. We have recently developed a new concept termed "switch-peptides" that allows the controlled onset of polypeptide folding and misfolding at physiologic conditions. As a major feature, the folding process is initiated by chemically or enzyme triggered $\mathrm{O}, \mathrm{N}-a c y l$ migration in flexible and soluble folding precursors containing Ser-or Thr-derived switch (S)-elements. The elaborated methodologies are exemplified for the in situ conversion of NPY- and Cyclosporine A-derived prodrugs, as well as for the onset and reversal of $\alpha$ and $\beta$ conformational transitions in A $\beta$ peptides. In combining orthogonally addressable switch-elements, the consecutive switching on of S-elements gives new insights into the role of individual peptide segments ("hot spots") in early processes of polypeptide self-assembly and fibrillogenesis.

Correspondence to: Manfred Mutter, Institute of Chemical Sciences and Engineering, Ecole Polytechnique Fédérale de Lausanne, EPFL, CH-1015 Lausanne, Switzerland; e-mail: manfred.mutter@epfl.ch

Contract grant sponsors: Swiss National Science Foundation; Debiopharm S.A., Lausanne.

\section{Inter Science ${ }^{\circledR}$}

() 2007 Wiley Periodicals, Inc.
Finally, the well-known secondary structure disrupting effect of pseudoprolines (IPro) is explored for its use as a building block (S-element) in switch-peptides. To this end, synthetic strategies are described, allowing for the preparation of $\Psi$ Pro-containing folding precursors, exhibiting flexible random-coil conformations devoid of fibril forming propensity. The onset of $\beta$-sheet and fibril formation by restoring the native peptide chain in a single step classify $\Psi$ Pro-units as the most powerful tool for inhibiting peptide self-assembly, and complement the present methodologies of the switch-concept for the study of fibrillogenesis. (C) 2007 Wiley Periodicals, Inc.

Biopolymers (Pept Sci) 88: 239-252, 2007.

Keywords: switch-peptides; folding precursors; selfassembling peptides; amyloid $\beta$ fibrillogenesis; enzymetriggered $\mathrm{O}, \mathrm{N}$-acyl migration; conformational transitions; pseudoprolines ( $\Psi$ Pro); $\alpha$-helix to $\beta$-sheet reversal; $\beta$-sheet disruption

This article was originally published online as an accepted preprint. The "Published Online" date corresponds to the preprint version. You can request a copy of the preprint by emailing the Biopolymers editorial office at biopolymers@wiley.com

\section{INTRODUCTION}

nraveling the relationship between peptide sequence, conformational and physicochemical properties as well as its impact on synthesis and biological function has been a major focus of our research for many years. ${ }^{1-3}$ In this context, the design and investigation of model peptides exhibiting a high propensity for secondary and tertiary 
structure formation proved to be ideal targets for elucidating the structural and dynamic parameters governing protein folding and function. ${ }^{4-6}$ Interestingly, the design of amphiphilic oligopeptides undergoing medium-induced conformational transitions as a first generation of "switch-peptides" in the early nineties $^{7,8}$ was considered primarily as a contribution to our understanding of the complex mechanism of peptide self-assembly and folding, whereas its importance as fundamental molecular processes in degenerative diseases has been recognized only more recently. ${ }^{9,10}$ For example, growing evidence suggests that conformational transitions of soluble amyloid $\beta(\mathrm{A} \beta)$ precursor molecules into aggregated $\beta$-sheet type forms play a key role in the deposition of amyloid plaques characteristic in Alzheimer's disease $(\mathrm{AD}){ }^{11,12}$ Similarly, $\alpha$-helix to $\beta$-sheet transitions are considered to be at the molecular origin of the transformation of the physiological PrPc form of the prion protein into pathologic PrPsc. ${ }^{13}$ The characteristic pathology of $\mathrm{AD}$ patients is associated with extracellular neuritic plaque deposits as well as intracellular neurofibrillary tangles in brain tissues. The plaques are composed of aggregates of the $\mathrm{A} \beta$ peptide, a 39-43 amino acid proteolytic fragment of a larger transmembrane protein termed amyloid precursor protein (APP). Although the pathological role of $\mathrm{A} \beta$ is unkown, this soluble peptide is present in all individuals at picomolar concentrations, ${ }^{13,14}$ and the transition from soluble $\mathrm{A} \beta$ to the non-native conformation and subsequent aggregation into fibrils appears intimately associated with disease progression. Accordingly, efforts to understand the structural nature of amyloid fibrils, to elucidate the self-assembly as well as the intermediates along the folding pathway, and to determine the factors involved in self-assembly are crucial for therapeutic intervention.

The insoluble amyloid fibrils and deposits have long been thought to be the neurotoxic species. ${ }^{15}$ However, increasing evidence now suggests a clear correlation between dementia and soluble $\mathrm{A} \beta$ oligomers. Oligomeric species have appeared as common entities associated with fibril formation of various peptides, including A $\beta, \alpha$-synuclein, polyglutamine tracts, and the larger prion proteins. ${ }^{16}$ The ability to aggregate and to form fibrils are both properties of many peptides and proteins associated with disease states or mutations in the primary sequence. Dobson and coworkers have shown that under conditions which destabilize the native state, proteins are prone to form amyloid with formation of regular, highly organized protein aggregates. ${ }^{17}$ In general, the underlying structure of amyloid fibrils is a cross- $\beta$ structure comprising $\beta$-strands of the peptide/protein arranged perpendicular to, and ribbon-like $\beta$ sheets parallel to the axis of the fibril. ${ }^{11}$

Currently, there are no known cures for AD, and although there are some drugs that have been approved for the treatment of the disease, the efficacy relies on their ability to delay the progression of the disease, rather than treating the underly- ing cause of disease. Neurological damage in AD is complex and has been shown to involve several different biochemical pathways, each of which provides a possible mechanism for therapeutic intervention. ${ }^{18}$

The majority of research in the amyloid field has focused primarily on designing small peptides that self-assemble into amyloid-like fibrillar structures as model systems to study amyloid formation or to fabricate materials with interesting physical properties. ${ }^{919-22}$ However, our knowledge of the mechanical and structural dynamics within $\beta$-sheet assemblies such as the amyloid fibrils remains limited.

\section{The Concept of Switch-Peptides}

Our laboratory has previously shown that incorporation of molecular switches into polypeptides, based on $O, N$ intramolecular acyl migration in situ, allows for the controlled induction or reversal of secondary structural transitions and self-assembly of small peptides. Based on the close relationship between the onset of secondary structure and physico-chemical properties of a growing peptide chain, notably the dramatic decrease in solubility due to self-association and $\beta$-sheet formation, ${ }^{1-6,23}$ the idea of conformationally dissecting the regular amide backbone by insertion of a switch-element $S$ at appropriate sites (resulting in sequences of chain length below the critical length $\left(n_{c}, \beta\right)$ for $\beta$ sheet formation) has emerged (Figure 1a).

As we will show here, switch-elements can be composed of depsipeptide (also called $O$-peptide or $O$-acyl isopeptide) units and/or pseudoprolines ( $\Psi$ Pro). So far, acyl transfer reactions have been the subject of extensive mechanistic studies, ${ }^{24}$ and their role in protein biosynthesis and splicing, ${ }^{25,26}$ peptide synthesis and solubilization, ${ }^{27-30}$ prodrug design ${ }^{31-36}$ and native chemoselective ligation strategies ${ }^{37-39}$ has found broad attention. Our focus over the last few years was directed toward the elaboration of the concept of "switch-peptides" for the study of peptide self-assembly, secondary structure formation, and disruption. ${ }^{40-42}$ Simultaneously, the use of $\mathrm{pH}$-induced $\mathrm{O}, \mathrm{N}$-acyl migrations for accessing "difficult sequences" has been independently described by the groups of Oliyai and Stella, ${ }^{32}$ Wieslaw et al., ${ }^{33}$ Kiso and coworkers, ${ }^{43} \mathrm{Ham}-$ ada et al., ${ }^{31}$ and Carpino and coworkers. ${ }^{44}$ For potential applications in vitro and in vivo, we developed a broad palette of orthogonal triggering systems, giving access to a sequential induction of $\mathrm{O}, \mathrm{N}$-acyl migrations as exemplified for $\mathrm{A} \beta$-derived switch-peptides. In exploring these novel techniques for the controlled in situ induction of structure and function (Figure 1b), a novel tool for elucidating early processes in peptide and protein misfolding relevant in degenerative diseases ${ }^{18}$ becomes available.

\section{EXPERIMENTAL PROCEDURES}

The switch-peptides were assembled according to standard Fmoc/ tBu-based solid-phase peptide synthesis, ${ }^{45}$ protocols as described 
a

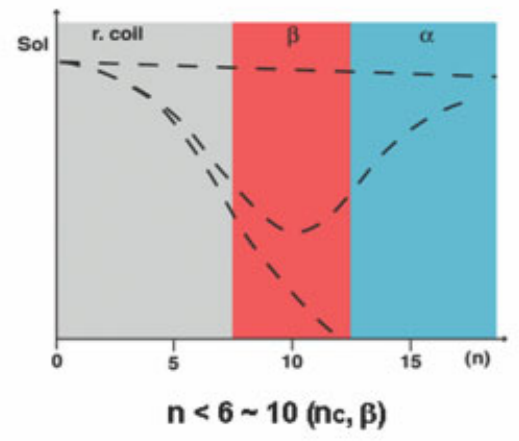

$\mathbf{N}$

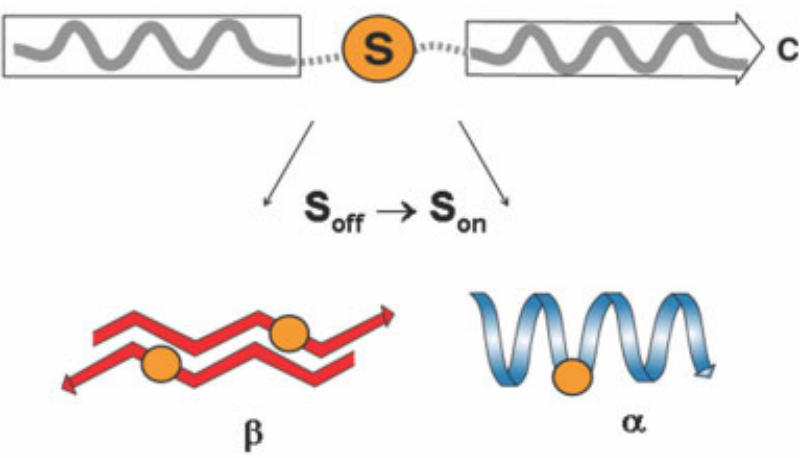

b

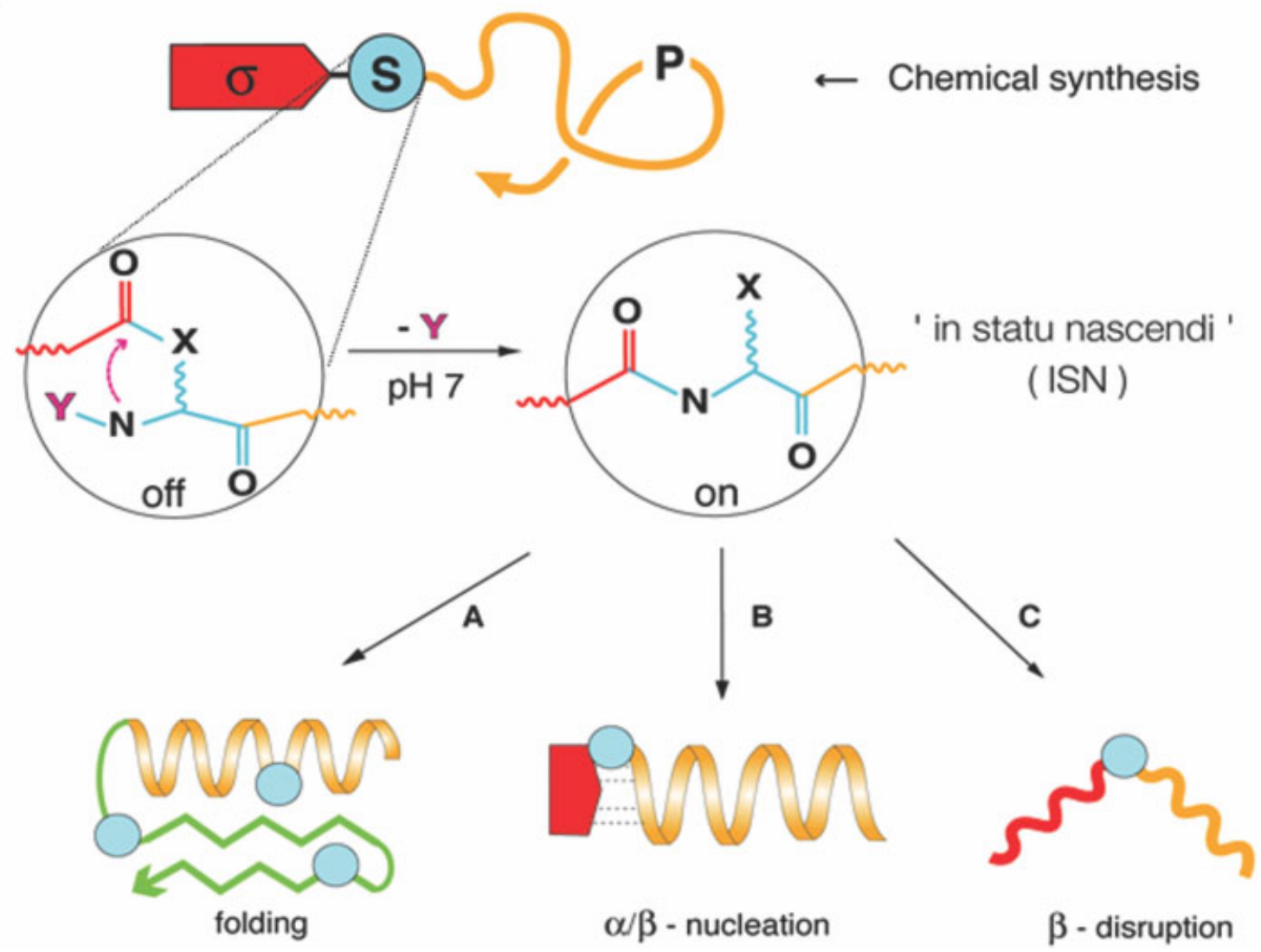

FIGURE 1 Switch-peptides as folding precursors. (a) The introduction of switch-elements $S$ (depsipeptide or pseudoproline ( $\Psi$ Pro) units) into a peptide chain interrupts the regular peptide backbone and prevents secondary structure formation. Even in the critical range of 6-10 residues during chain elongation, $\beta$-sheet formation in the $S_{\text {off }}$ state is hampered, resulting in a drastically increased solubility of the peptide. After switching on $S$, the onset of folding is triggered leading to sequence dependent $\beta$-sheet or $\alpha$-helical structures; (b) Concept of in statu nascendi (ISN)-induced conformational transitions. Switch-peptides are assembled by chemical synthesis and consist of a target peptide $\mathrm{P}$, a switch element $\mathrm{S}$, and a conformational induction unit sigma $(\sigma)$. By triggering $\mathrm{X} \rightarrow \mathrm{N}$ acyl migration upon removal of $\mathrm{Y}$ (enzymatic or by change of $\mathrm{pH}$ ), the establishment of a regular peptide bond between $\sigma$ and $\mathrm{P}$ results in the onset of conformational changes, typically from a flexible random-coil $\left(\mathrm{S}_{\text {off }}\right.$-state $)$ to a folded $\left(\mathrm{S}_{\text {on }}\right)$ state. In applying peptidomimetics and templating effects, the $\sigma$-induced onset (strategy A), nucleation (B), and disruption (C) of secondary and tertiary structures offers a tool for the study of conformational transitions as early events in degenerative diseases. 


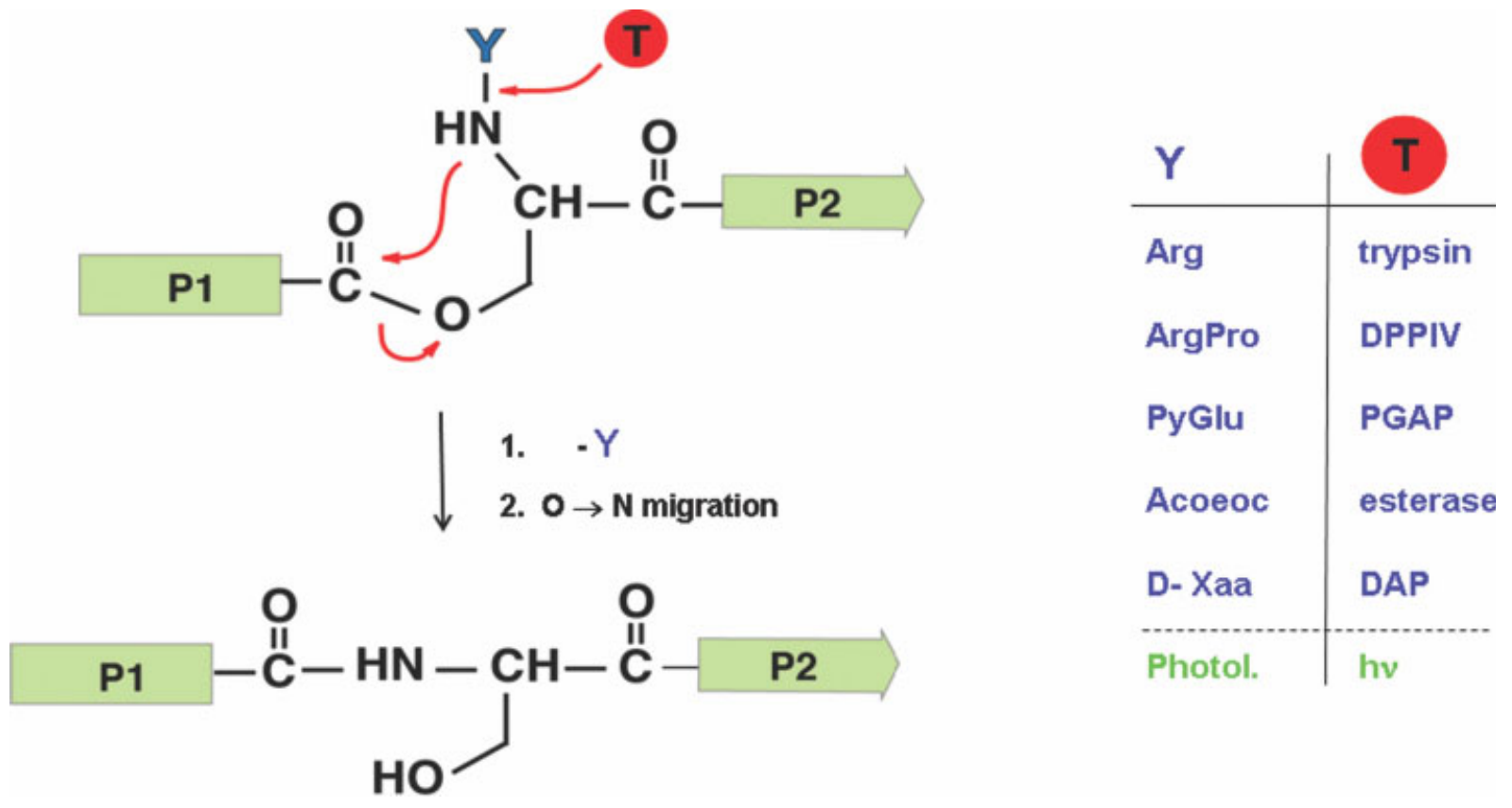

FIGURE 2 Orthogonal triggering systems for applications at physiologic conditions. The $\mathrm{N}(\mathrm{Y})$ protected switch-peptide containing an $\mathrm{O}$-acyl isoserine $\left(\mathrm{S}_{\text {off }}{ }^{-}\right.$-state $)$as $\mathrm{S}$-element is transformed to the native state $\left(\mathrm{S}_{\mathrm{on}}\right)$ by chemical $(h v)$ or enzymatic cleavage of $\mathrm{Y}$ in vitro and in vivo, triggering spontaneous intramolecular acyl migration at physiologic $\mathrm{pH}$.

before. $^{40,41}$ The switch-elements were introduced manually by coupling the corresponding protected depsidipeptides ${ }^{40}$ (for a minireview, see Ref. 43). Pseudoproline units were introduced as Fmoc$\mathrm{Xaa}-\Psi^{\mathrm{Me}, \mathrm{Me}}$ pro dipeptides (commercially available at Novabiochem/Merck, Switzerland). The Ncaps used here are described in Ref. 46. All peptides were characterized by analytical HPLC (>95\%) and ESI-MS. Circular dichroism (CD) spectra were recorded on a JASCO J-810. For electron microscopy (EM) studies, the peptide solution was absorbed on to glow-discharged, carbon-coated copper grids. Grids were washed with two drops of water and stained with two drops of freshly prepared $0.75 \%(\mathrm{w} / \mathrm{v})$ uranyl acetate (Electron Microscopy Sciences). Specimens were inspected with a Philip CIME 12 electron microscope, operated at $80 \mathrm{kV}$. Digitized photographs were recorded with a slow scan CCD camera (Gatan, Model 679).

\section{RESULTS AND DISCUSSION}

\section{Triggering O,N-Acyl Migration In Situ ${ }^{40-42}$}

For potential applications in vitro and in vivo, we have explored a series of orthogonal triggering systems making use of chemical and enzymatic methodologies (Figure 2). Due to their proteinogenic cleavage sites, enzymatic triggering is particularly useful for modulating the $O, N$-acyl migration step in vitro. As a representative example, we applied the ISN-induction of conformational transitions for the onset of biological function, making use of structure-activity relationship studies on neuropeptide Y (NPY) and its shorter analogues. ${ }^{47,48}$ As shown previously, the C-terminal peptide NPY (21-36) corresponds to the minimal chain length for retaining significant binding capacity to NPY receptor Y2, notably in a helical state as bioactive conformation. When the two peptide blocks NPY (21-31) and NPY (33-36), both with $n<n_{\mathrm{c}}, \alpha$ are conformationally decoupled by insertion of switch element $S$ (derived from $\mathrm{Thr}^{32}$, Figure 3a), the resulting switch peptide adopts a random-coil conformation and shows no binding to $\mathrm{Y} 2\left(\mathrm{IC}_{50} \gg 10 \mu \mathrm{M}\right)$. When native NPY (21-36) is induced by DPPIV-triggered $O, N$-acyl migration $\left(t_{1 / 2}=20 \mathrm{~min}\right.$ at $\mathrm{pH} 5.8, t_{1 / 2}<2$ min at physiological $\mathrm{pH})$ a random-coil to helix transition is observed (typical CD curves, Figure 3a), paralleled by the onset of biological function $\left(\mathrm{IC}_{50}=0.8 \mathrm{nM}\right)$.

Similarly, photolytically cleavable N-protecting groups have been explored for switch-peptides derived from Cyclosporine A (CsA). To this end, CsA is transformed to its $\mathrm{N}$ protected isoacyl derivative ${ }^{28,29}$ (Figure 3b). Most notably, the resulting switch-peptide proved to be devoid of any immunosuppressive activity due to the dramatic changes in the backbone structure $\left(\mathrm{S}_{\text {off }}\right.$-state). The conversion to its biologically active state at physiologic conditions was achieved by photolytic cleavage of the $\mathrm{N}$-protecting group. As observed previously, the subsequent $\mathrm{O}, \mathrm{N}$-acyl migration turned out to be slow ( $t_{1 / 2}=$ several hours), pointing to considerable conformational constraints in the cyclic peptide 
a

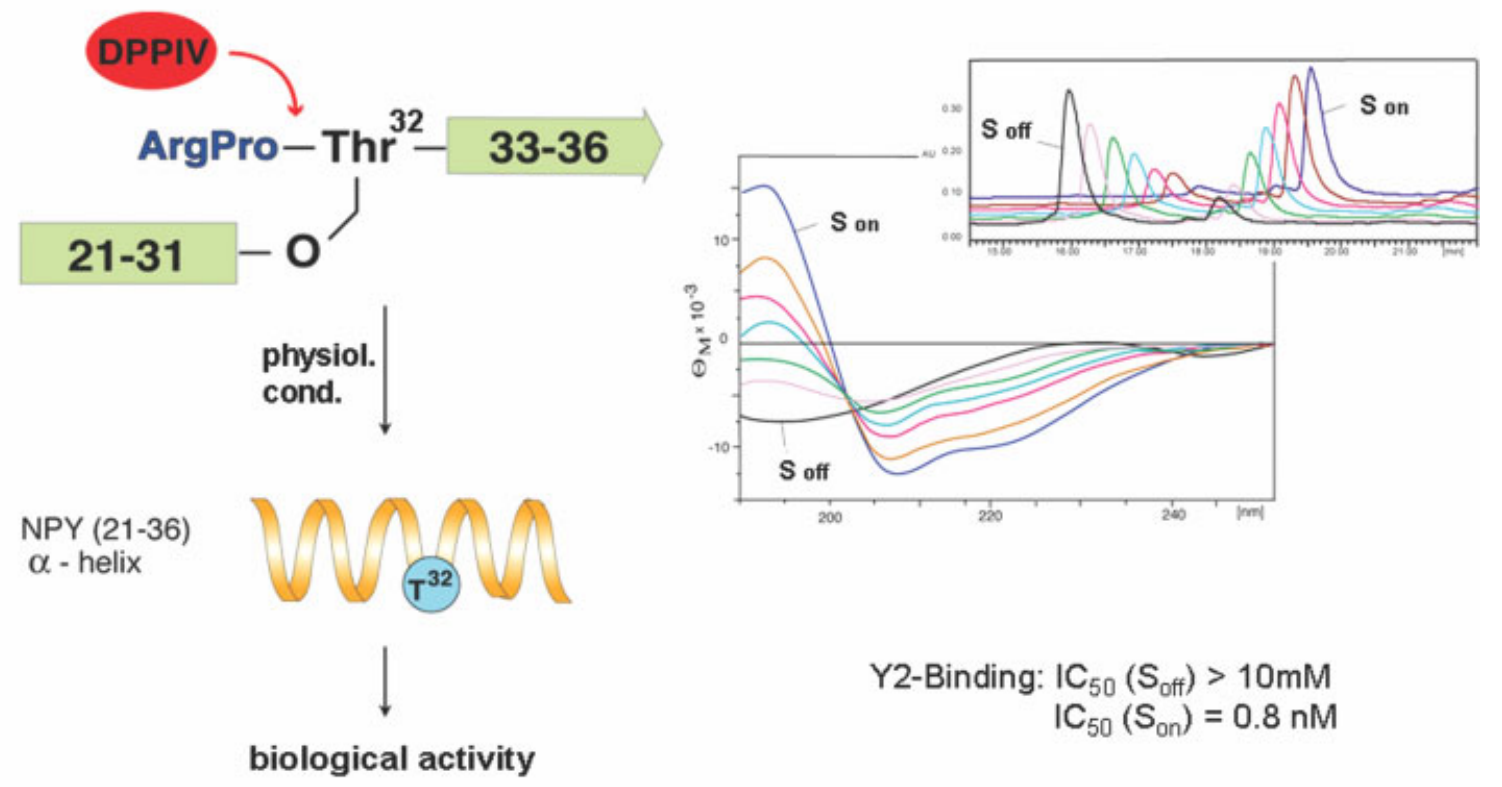

b

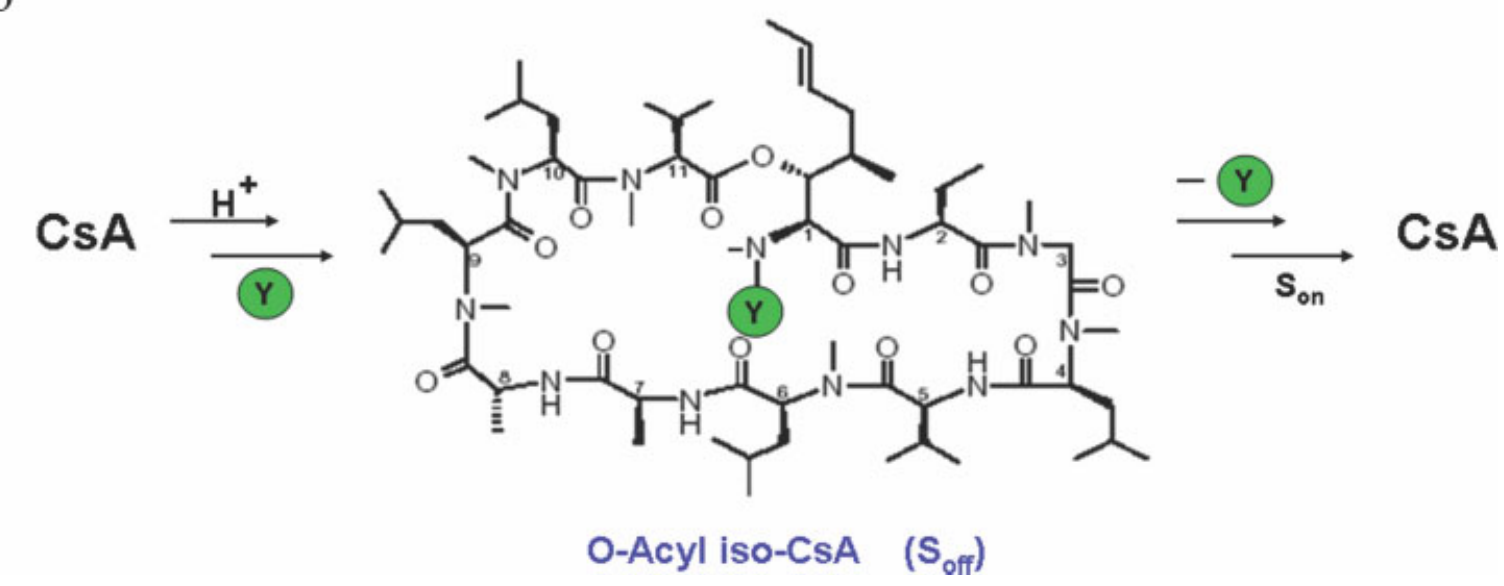

FIGURE 3 ISN induction of structure and function. (a) NPY (21-36) has the minimum chain length for retaining significant binding capacity to NPY receptor 2, notably in a helical state as bioactive conformation. Conformational decoupling by insertion of a $\mathrm{Thr}^{32}$-derived switch-element $\mathrm{S}$ results in a switch-peptide that adopts a random coil conformation and shows no binding to Y2 $\left(\mathrm{IC}_{50}>10 \mathrm{mM}\right)$. Upon DPPIV triggered $\mathrm{O}, \mathrm{N}$-acyl migration at physiologic conditions, NPY (2136) is restored and a random coil to $\alpha$-helix transition can be observed by CD paralleled by the onset of biological function $\left(\mathrm{IC}_{50}=0.8 \mathrm{nM}\right.$ ). Inset: HPLC monitoring of the acyl migration; (b) Switch-peptides as "soft prodrugs": CsA is transformed to N(Y)-protected $O$-acyl isoCsA ( $\left.\mathrm{S}_{\text {off }}\right)$. By photolytic cleavage $(\mathrm{Y}=\mathrm{Nvoc}), \mathrm{O}, \mathrm{N}$-acyl migration converts the prodrug to its native state $\left(\mathrm{S}_{\mathrm{on}}\right)$.

during $\mathrm{O}, \mathrm{N}$-acyl migration. The availability of various triggering systems for the induction of biological function opens interesting perspectives in the design of "soft prodrugs".

\section{Controlled Induction of $\beta$ to $\alpha$ Conformational Transitions in A $\beta$ Peptides}

As $\beta$-sheet formation is considered as a nucleation step in peptide self-assembly, notably regarded as key process in
(A $\beta)$ self-assembly and fibrillogenesis, the reversal of this conformational transition has recently found broad attention. ${ }^{9,10,21,49,50}$ Despite the extreme stability of $\beta$-sheet rich amyloid fibrils to proteases, acid and chemical denaturants, increasing evidence from human, animal models, and in vitro studies point to a dynamic structure within amyloid fibrils, and suggest that the process of amyloid formation is reversible. ${ }^{51} \mathrm{To}$ investigate the feasibility of disrupting or reversing amyloid for- 
a

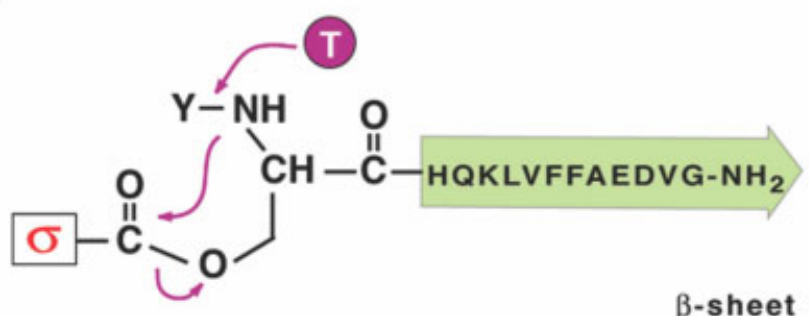

1. $-Y$

2. $\mathrm{O} \rightarrow \mathrm{N}$ migration

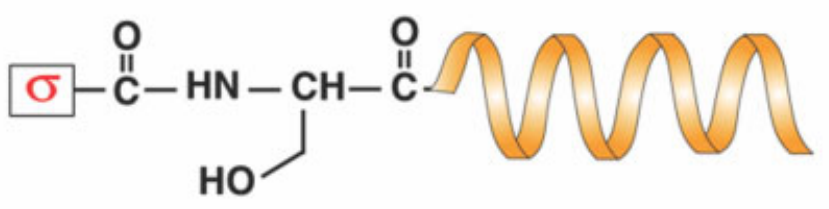

$\alpha$-helix

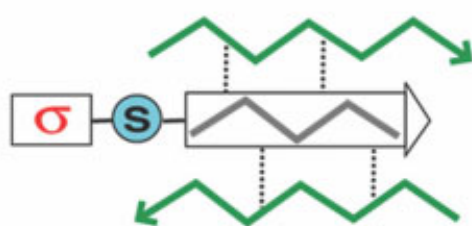

$\beta$-recognition

E $\$ Helix induction

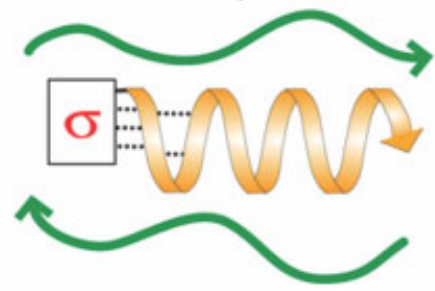

$\beta$-disruption

$\mathrm{b}$
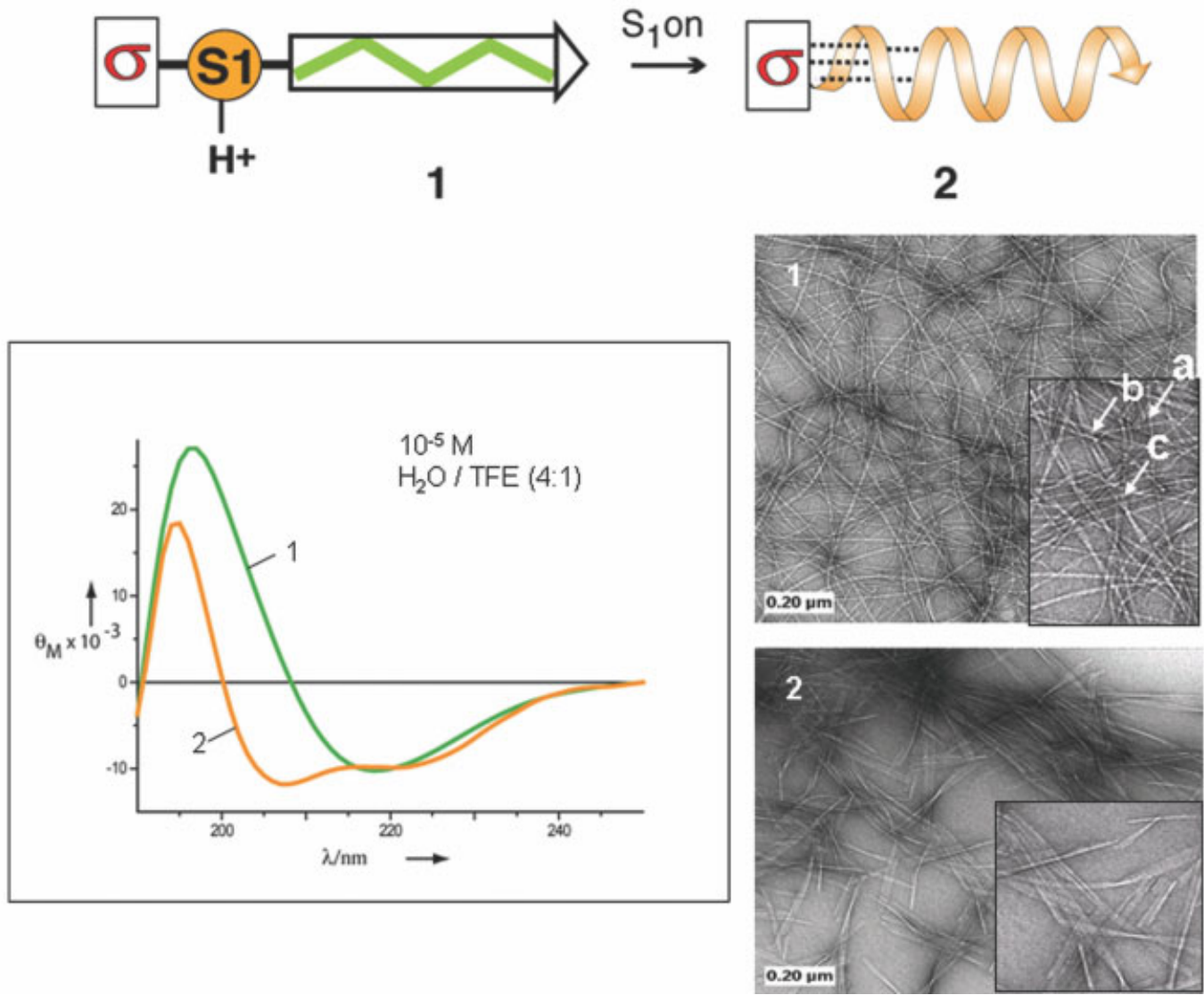

FIGURE 4 Adapted from [52]. Switch-peptides for the Ncap $(\sigma)$-induced $\beta$-sheet to $\alpha$-helix reversal and disruption of $\mathrm{A} \beta$ fibrils. (a) The peptide sequence $\mathrm{A} \beta$ (14-25) (1) is linked to a helix-inducing lactam-bridged template (Ncap $(\sigma)=$ Ac-[cyclo-1-5]-KARAD) via a Ser-derived switch-element $S$ (O-acyl isopeptide unit, $\mathrm{S}_{\text {off }}$-state). By removing the N-protecting group $\mathrm{Y}$, spontaneous $\mathrm{O}, \mathrm{N}$-acyl migration results in the onset of the helix-inducing effect of $\sigma$, resulting in a helical structure (left). By the onset of $\sigma$, a controlled conformational transition of type $\beta$-sheet to $\alpha$-helix is induced, resulting in a disruption

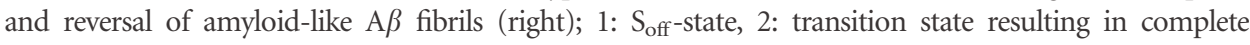
disappearance of fibrils (not shown); (b) Monitoring conformational transitions of peptide $\mathbf{1}$ by $\mathrm{CD}$ ( $c=$ $5 \times 10^{-5} M ; T=25^{\circ} \mathrm{C}$ ). Buffer $\mathrm{pH} 4.5 / \mathrm{TFE}(4: 1), \mathrm{S}_{\text {off }}$ (green); buffer $\mathrm{pH} 7 / \mathrm{TFE}(4: 1), \mathrm{S}_{\text {on }}$ (yellow). 


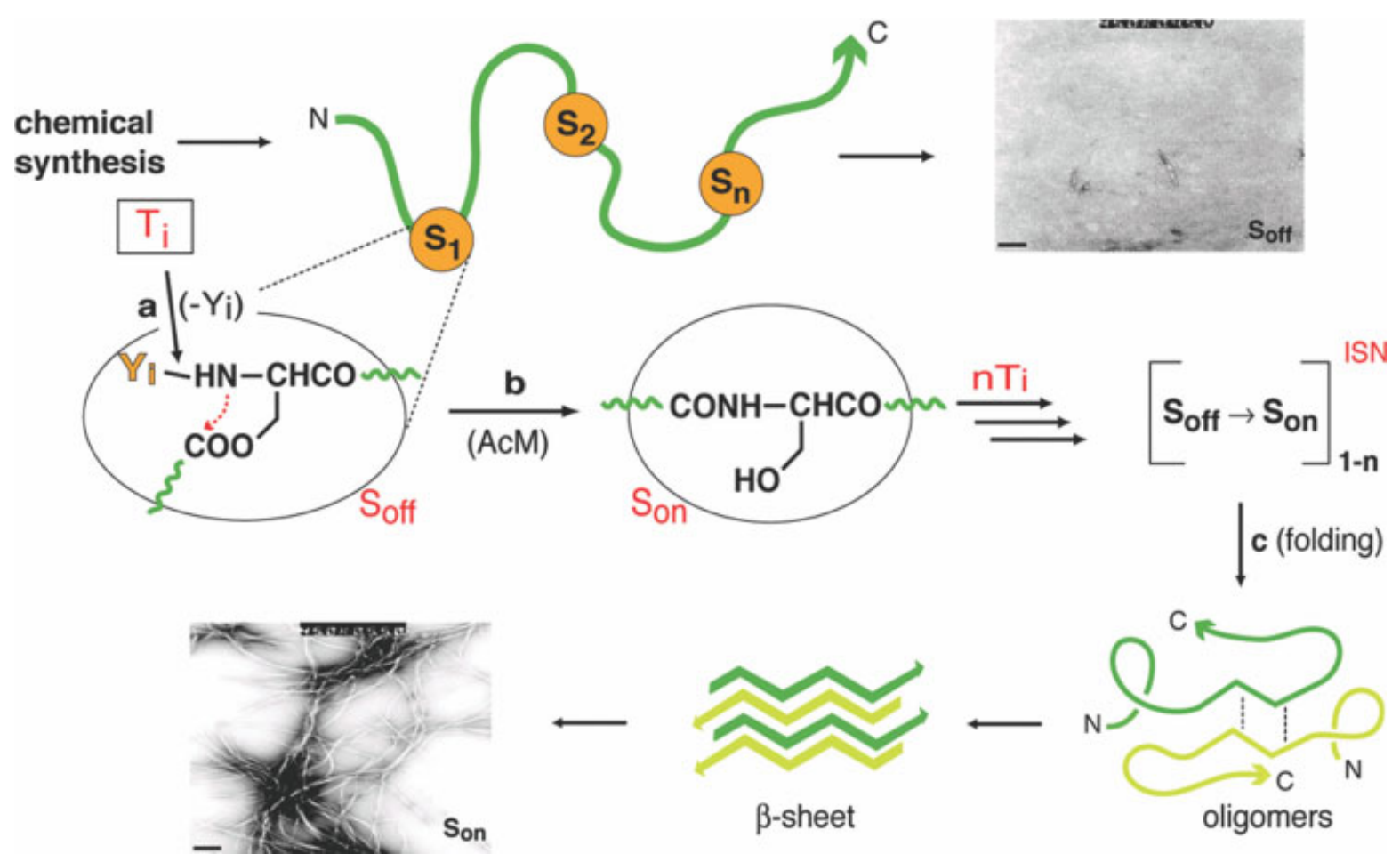

FIGURE 5 The concept of switch-peptides for the in situ induction of folding processes relevant in degenerative diseases. Switch-peptides contain multiple N(Y)-Ser-, Thr-, or Cys-derived acyl isoresidues as switch (S)-elements, disrupting the regular amide backbone (nonfolded, flexible state $\mathrm{S}_{\text {off }}$, absence of fibrils). Consecutive triggering (chemically or enzymatically, step a) of $\mathrm{O}, \mathrm{N}$-acyl migrations (step b) restores the native backbone $\left(\mathrm{S}_{\mathrm{on}}\right.$-state), initiating folding events (step c) such as self-assembly, $\beta$-sheet and fibril formation in statu nascendi (ISN) of the native molecule. The experimental access to early molecular events in degenerative diseases represents a starting point for the rational design of inhibitors of protein misfolding.

mation through controlled induction of $\beta$-sheet to $\alpha$-helix transformation, we designed a switch-peptide ${ }^{52}$ containing the fibril-forming sequence HQKLVFFAEDVG, corresponding to $\mathrm{A} \beta$ (14-25), connected to a helix nucleating Ncap $[\sigma]^{46}$ via a Ser-derived switch-element (S) (Figure 4a). The A $\beta$ (14-25) peptide contains the amino acid residues $16-20$ that are essential for fibril formation in the full length $\mathrm{A} \beta$ peptide and readily forms amyloid fibrils in vitro. As Ncap, we chose the cyclic pentapeptide sequence Ac-(cyclo-1-5)-KARAD, which contains a lactam bridge formed between the Asp and Lys residues at positions $i$ and $i+4$ respectively. This type of lactam bridge effectively constrains the residues into an enforced $\alpha$-helical turn and, when incorporated into a larger peptide, can greatly increase the overall helicity. ${ }^{53}$ To examine the solution properties of peptide 1 in the $S_{\text {off }}$ - and $S_{\text {on }}$-states (Figure $4 \mathrm{~b}$ ), its secondary structure and aggregation state was probed by CD and EM studies. In the $\mathrm{S}_{\text {off }}$-state ( $\mathrm{pH}$ 4.5, $50 \mathrm{mM}$ acetate, $150 \mathrm{mM} \mathrm{NaCl}$ ) and at concentrations between $10-100 \mu M$, peptide 1 displays a CD spectra that is indicative of a predominantly $\beta$-sheet structure. Activation of the helix-inducing $\operatorname{Ncap}\left(\mathrm{S}_{\mathrm{on}}\right)$ via a $\mathrm{pH}$-induced
$\mathrm{O}, \mathrm{N}$-acyl migration is not sufficiently strong to overcome the intrinsic $\beta$-sheet propensity of $\mathrm{A} \beta$ (14-24). However, in the presence of $25 \%$ TFE as $\alpha$-helix stabilizing cosolvent, an unprecedented structural transition from a $\beta$-sheet in the $\mathrm{S}_{\text {off }}$-state to an $\alpha$-helix in the $S_{\text {on }}$-state is observed and is nearly complete within $5 \mathrm{~min}$ at room temperature.

EM studies revealed that the transition from $\beta$-sheet to $\alpha$ helical structure is accompanied by a dramatic change in the morphology of the fibrils. Figure $4 \mathrm{~b}$ shows negatively stained micrographs of peptide $\mathbf{1}$ before and after triggering the switch element in the presence of $25 \%$ TFE. In the $\mathrm{S}_{\text {off }}$-state, peptide 1 self-assembles into long ( $>2 \mu \mathrm{m})$ unbranched fibrils with an average diameter of $3.3 \mathrm{~nm}$. Lateral association of these thin fibrils results in the formation of twisted amyloid-like fibrils. Only fibrils with a diameter greater than $10 \mathrm{~nm}$ exhibited a regular twisting with a periodicity of $\sim 250 \mathrm{~nm}$. Interestingly, upon triggering the $O \rightarrow N$ acyl migration $\left(\mathrm{S}_{\mathrm{on}}\right.$ state), the fibrillar assemblies rearrange to predominantly ribbon-like structures. These assemblies appear to form as a result of the lateral association of several (3-6) nontwisted filaments, $\sim 10 \mathrm{~nm}$ in diame- 


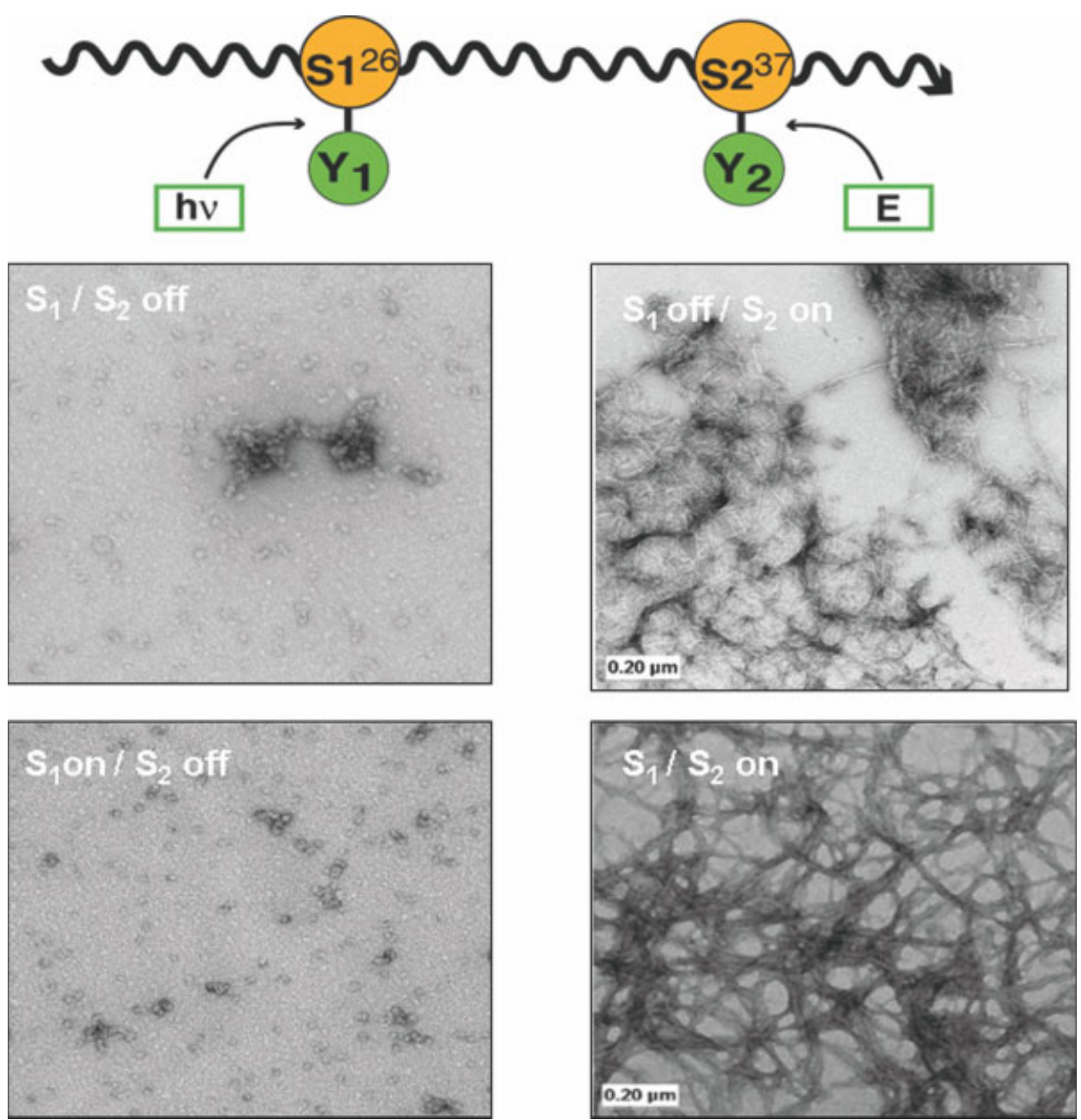

FIGURE 6 Consecutive triggering of $O, N$-acyl migration in $\left[\mathrm{Ser}^{37}\right] \mathrm{A} \beta(1-42)$ switch-peptide as folding precursor. Selective triggering of $\mathrm{O}, \mathrm{N}$-acyl migration by photolytic (S1) and enzymatic (DPPIV, S2) cleavage of $\mathrm{Y}_{1}$ (Nvoc) and $\mathrm{Y}_{2}$ (ArgPro) results in the delineation of "hot spots" in fibrillogenesis as shown by TEM studies. In the $S_{\text {off }}$-state $\left(S_{1} / S_{2}\right.$ off) $\left[\operatorname{Ser}^{37}\right] A \beta(1-42)$ shows no tendency for fibril formation. After first triggering $S 1$ upon photolytic cleavage of $\operatorname{Nvoc}\left(S_{1}\right.$ on $/ S_{2}$ off) no oligomeric states or fibrils can be observed after 3 days indicating that restoring $\mathrm{A} \beta(1-37)$ is not sufficient to mimic the properties of $\mathrm{A} \beta(1-42)$. Subsequent enzyme triggering of $\mathrm{S} 2$ leads to the formation of characteristic $\mathrm{A} \beta$ fibrils. It is important to note, that in reversing the sequential order of switching on S1 and S2, i.e. first enzyme cleavage (S2) followed by photolysis (S1), [Ser $\left.{ }^{37}\right]$ $\mathrm{A} \beta(1-42)$ in the $\mathrm{S}_{1}$ off/ $\mathrm{S}_{2}$ on-state shows oligomeric states and fibril-like structures of a different fibrillar morphology compared to full length $\left[\mathrm{Ser}^{37}\right] \mathrm{A} \beta(1-42)\left(\mathrm{S}_{1}\right.$ on $/ \mathrm{S}_{2}$ on). This result points to the pivotal role of the $\mathrm{C}$-terminal chain in the process of fibrillogenesis.

ter. The ribbon-like fibrils appear to fragment into short structures with an average length that does not exceed $0.45 \mu \mathrm{m}$, whereas the fibrils formed in the $S_{\text {off }}$-state are several microns in length. The fibrillar morphology formed in the $S_{\text {off }}$-state resembles those observed for disease associated proteins such as A $\beta$ and $\alpha$-synuclein. Using peptide 1 , we were able to investigate the feasibility of disrupting or reversing amyloid formation through controlled induction of $\beta$-sheet to $\alpha$-helix transformation of the self-assembled peptides within the amyloid structure. The experimental data offer new insights into the stability and structural properties of amylod fibrils. Furthermore, these studies demonstrate for the first time that structural changes in protein domains ${ }^{49}$ that are not involved in amyloid formation could have significant impact on the stability and structural dynamics of amyloid fibrils.

\section{Elucidating the "Hot Spots" of Peptide and Protein Misfolding}

The selective, consecutive switching on of S-elements (Figure 5) in switch-peptides applying orthogonal triggering systems 


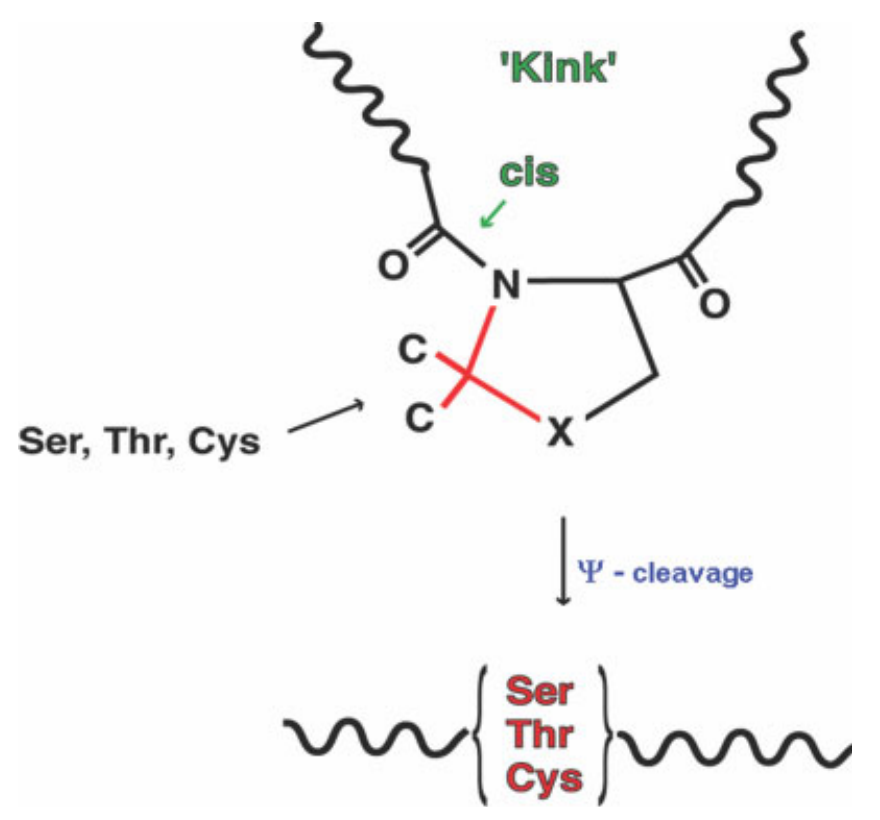

FIGURE 7 Pseudoprolines ( Pro) as structure disrupting, solubilizing protection technique for Ser, Thr $(\mathrm{X}=\mathrm{O})$ and Cys $(\mathrm{X}=\mathrm{S})$. The insertion of a cis-amide bond in C2-dimethyl $\Psi$ Pro derivatives results in a kink conformation, preventing self-association, aggregation and secondary structure formation.

(Figure 2) allows for the elucidation of nucleation sites ("hot spots") in early processes of fibrillogenesis. For proof of concept, we have designed an A $\beta$ (1-42) derived switch-peptide containing two orthogonal S-elements. For this purpose, a photolytically (Nvoc) and enzymatically (ArgPro) cleavable group was inserted at position $\mathrm{S}_{1}{ }^{26}$ and $\mathrm{S}_{2}{ }^{37}$ (replacing native $\mathrm{G}^{37}$ ), respectively (Figure 6$)$. In the $S_{\text {off }}$-state $\left(S_{1 / 2}\right.$ off), the peptide shows a flexible random coil structure in the $\mathrm{CD}$ at physiologic conditions, exhibits excellent solubility, and does not form fibrils after several days as shown by TEM studies. In first triggering $\mathrm{O}, \mathrm{N}-$ acyl migration at $S_{1}$ (photolytic cleavage of Nvoc), the $A \beta$ derived switch-peptide retains its high solubility, and no oligomeric states or fibrils can be observed after three days $\left(S_{1}\right.$ on $/ S_{2}$ off). However, by the subsequent addition of the enzyme DPPIV for triggering $S_{2}$, the onset of the characteristic $A \beta$ fibrils is observed as revealed by TEM studies, paralleled by precipitation.

Obviously, the establishment of the native sequence $\mathrm{A} \beta$ (1-37) does not result in the typical features known for full length $\mathrm{A} \beta$ (1-42). In contrast, in reversing the sequential order of switching on $S_{1}$ and $S_{2}$, i.e. first adding $\operatorname{DPPIV}\left(\mathrm{S}_{2 \text { on }}\right)$, the in situ creation of native $\mathrm{A} \beta(27-42)$ results in the formation of oligomeric states followed by fibril like structures $\left(\mathrm{TEM} \mathrm{S}_{1 \mathrm{off}} / \mathrm{S}_{2 \mathrm{on}}\right.$, Figure 6 ), again paralleled by a dramatic decrease in solubility, pointing to a pivotal role of the C-terminal chain in the process of fibrillogenesis.

Interestingly, the subsequent switching on of $S_{2}\left(S_{1} / S_{2}\right.$ on $)$ results in the formation of mature $\mathrm{A} \beta$ fibrils, indicating that the substitution of $\mathrm{Gly}^{37}$ by $\mathrm{Ser}^{37}$ does not significantly alter the conformational properties of native $\mathrm{A} \beta(1-42)$. The ability to control the structure and morphology of aggregates suggests that engineering specific switch-elements and/or structure templating motifs within amyloid forming proteins and peptides would allow to correlate structural differences between the different amyloid morphologies with toxicity. The flexibility in incorporating multiple, orthogonally protected switchelements that can be triggered in a selective and specific manner using chemical, enzymatic, and/or photolytic procedures (Figure 2) opens new possibilities in protein engineering and the design of "smart" materials with tunable structural, functional, and physicochemical properties.

\section{Pseudoprolines as Structure-Disrupting Protection Technique}

During our extensive work on the study of the relationship between conformational preference of a growing peptide chain and its impact upon its physical and chemical properties, ${ }^{3,23}$ the particular role of Pro in disrupting potentially secondary structure forming peptides has been noticed very early. ${ }^{54}$ In particular, the finding of its tendency to prevent $\beta$-sheet conformations and aggregation, paralleled by a pronounced solubilizing effect ${ }^{55,56}$ had a strong impact upon solid-phase synthesis. Most notably, our systematic studies in collaboration with C. Toniolo's group on the onset and disruption of $\beta$-sheet structures of oligopeptides set the stage for taking conformational effects upon solubility, solvation, and reaction kinetics in the synthesis of hydrophobic, self-associating peptides (later termed "difficult sequence") ${ }^{57,58}$ as strategic factors in peptide synthesis. Based on these observations, we have noticed that the temporary transformation of serine (Ser), threonine (Thr), and cysteine (Cys) residues into cyclic structures by established procedures results in proline-like compounds, termed pseudoprolines, (Figure 7). ${ }^{59-61}$ The physical, chemical, and conformational properties of the resulting oxazolidine- or thiazolidine systems prove to be strongly dependent upon the character of the $\mathrm{C} 2$ substituents of the cyclic ring.

The facile synthetic accessibility of $\Psi$ Pro building blocks exhibiting differential chemical stabilities and cis/trans ratios allows to mimic and even to enhance the unique properties of Pro in natural peptides and proteins opening a broad palette of applications in bioorganic chemistry (for recent reviews of pseudoprolines, see Ref. 62).

\section{Pseudoproline as Switch-Element in Folding}

\section{Precursors}

So far, pseudoprolines have found applications in providing solubilizing and secondary-structure disrupting building blocks for the synthesis of difficult peptide sequences and for 


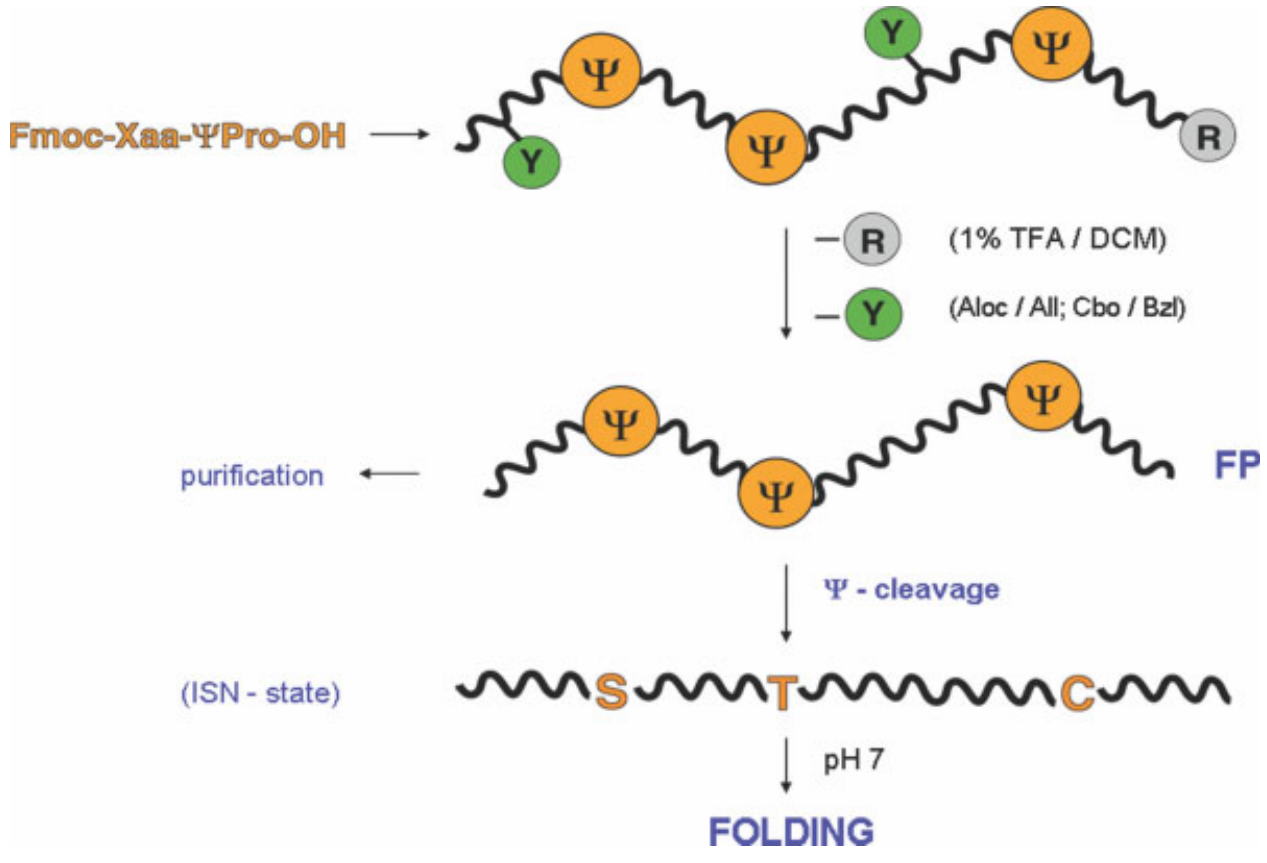

FIGURE 8 Strategy for the use of $\Psi$ Pro-units as switch-elements in folding precursors. The selective resin cleavage (Sieber, Sasrin) and subsequent removal of the side chains (Y) results in a flexible, soluble folding precursor (FP). Acidic cleavage of the cyclic ring system in $\Psi$ and subsequent neutralization results in the onset of self-assembly and folding at physiologic conditions.

the reversible induction of cis-amide bonds into peptide backbones (Figure 7). Here, the use of $\Psi$ Pro systems as temporary protection technique for Ser-, Thr- or Cys-containing peptides proved to strongly improve the yields and purity of otherwise difficult sequences, as shown by a steadily increasing number of comparative studies. ${ }^{44,62}$ Most notably, the use of C2-dimethyl substituted $\Psi$ Pro building blocks results in the formation of a cis-amide bond in the regular peptide backbone ("kink conformation"), thus preventing $\beta$-sheet formation and self-aggregation during peptide synthesis. As most native peptides contain one or several Ser, Thr, or Cys residues (depending on the target, a conservative replacement of other residues e.g. Gly or Ala by Ser or Thr is tolerable), the $\Psi$ Pro strategy appears particularly appealing for the chemical synthesis of long peptides. In standard Fmoc strategy, ${ }^{63}$ the final cleavage of the target peptide from an acid labile resin results in a completely deprotected peptide including $\Psi$ Pro ring opening, i.e. transformation of the $\Psi$ Pro units to the corresponding "native" Ser, Thr, or Cys. For preserving the solubilizing, structure disrupting effect of $\Psi$ Pro during purification steps, alternative protection schemes have to be applied. The use of orthogonal protection techniques (e.g. allyl/alloc side chain protection, super acid labile linkers) gives access to $\Psi$ Pro-containing, side chain unprotected (water soluble) peptides, which can be regarded as versatile folding precursors (Figure 8). In applying the depicted strategy, the $\Psi$ Pro-containing crude peptide can be readily purified and is obtained as a chemically stable folding precursor. Most notably, the transformation into its regular backbone structure by restoring the native Ser, Thr, and/or Cys residues can be achieved in a single step under mild conditions, setting off the folding process. As a prototype, we have prepared the otherwise "inaccessible" decapeptide (Ser-Leu) 5 as $\Psi \mathrm{PrO}_{5}$-containing folding precursor according to the strategy shown in Figure 8. Due to the pronounced structure disrupting effect of the C2-dimethyl $\Psi$ Pro at position 5, peptide 1 (Figure 9) exhibited excellent solubility in organic and aqueous media, adopting a flexible random coil structure $(\mathrm{CD}$, curve 1). In opening the cyclic structure of $\Psi \mathrm{Pro}^{5}$ by the addition of acid followed by adjusting the $\mathrm{pH}$ to 7.0 , a conformational transition to a $\beta$-sheet structure (typical CD, IR amide II bands) is observed, paralleled by the onset of fibril formation (TEM) and precipitation. Preliminary studies on YPro-containing A $\beta$ (1-42) peptides confirm the pronounced structure disrupting and fibril preventing effect of YPro, rendering them as ideal building blocks (S-elements) in the future design of folding precursors.

Depsipeptide units interrupt the regular peptide backbone by the presence of an ester bond together with a flexible $\mathrm{C}-\mathrm{C}$ bond, resulting in a secondary structure destabilizing 


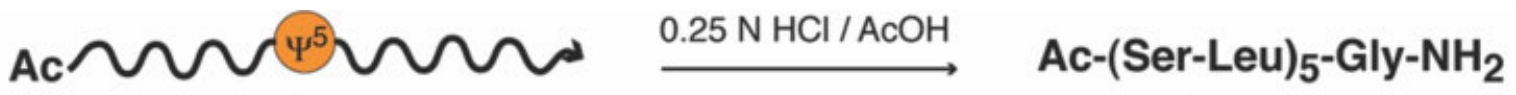 \\ 1 \\ 2}

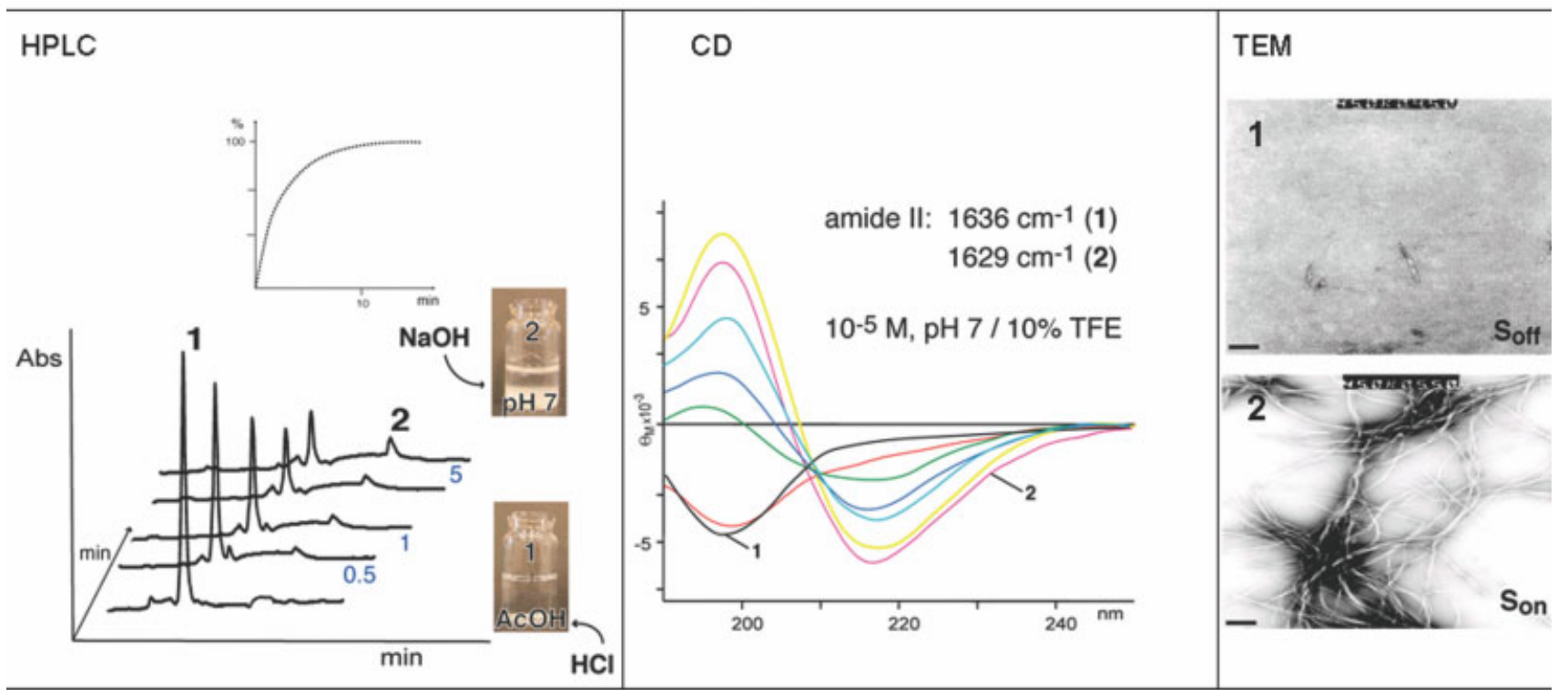

FIGURE 9 The insertion of a $\Psi$ Pro $^{5}$ in the self-assembling model peptide 2 results in a folding precursor (1) exhibiting high solubility (e.g. in $\mathrm{AcOH}$ or buffer $\mathrm{pH} 7$ ) and no tendency for secondary structure (CD, curve 1 ) or fibril formation (TEM). In cleaving the $\Psi$ Pro system, peptide 1 transforms to peptide 2 forming a $\beta$-sheet (CD, curve 2), paralleled by precipitation (HPLC peak 2 ), and the onset of fibrils (TEM).

effect. However, we have noticed tendencies of $O$-acyl isopeptides for $\beta$-sheet and fibril formation in the presence of nucleating templates. As the structure disrupting effect of YPro-residues resides in the formation of a kink conformation due to the presence of cis amide bond, the alignment and subsequent growth to a given $\beta$-sheet template should be strongly hindered. To prove this hypothesis, we compared depsipeptide and $\Psi$ Pro-containing peptides of high potential for self-association. Surprisingly, the model peptide (SerLeu $)_{5}$ containing a single depsipeptide bond at Ser $^{5}$ showed fibril formation, whereas the corresponding $\Psi \mathrm{Pro}^{5}$-peptide did not show any fibrils under identical experimental conditions (Figure 10), in support of the above rational. This result indicates a more pronounced $\beta$-sheet and fibril-disrupting effect of a $\Psi$ Pro compared to a depsipeptide unit making $\Psi$ Pro building blocks ideal complementary switch-elements in the design of folding precursors.

\section{CONCLUSIONS AND PERSPECTIVES}

Switch-peptides aim to separate the establishment of the peptide sequence by chemical synthesis from the process of peptide self-association and folding. According to the elaborated concepts, the incorporation of switch-elements (depsipeptide or pseudoproline units) allows for the efficient synthetic access of folding precursors, where the regular amide bond system is conformationally dissected, resulting in flexible chains of favorable physicochemical properties during chain elongation and purification. The availability of selectively addressable switch-elements according to Figure 11 will allow to push the limit of present solid-phase peptide synthesis up to higher chain lengths, independent of the conformational preferences of the native sequence, as the process of folding and aggregation is suppressed. Furthermore, the access of polypeptides and even proteins exhibiting high tendency for self-association and misfolding, notably in the context of neurodegenerative diseases, will become accessible by incorporating the elaborated methodologies into modern strategies of convergent syntheses and peptide ligation techniques. ${ }^{64,65}$

In perspective, switch-peptides will become a powerful chemical tool for addressing fundamental biological questions, notably in the field of peptide and protein self-assembly, misfolding, and fibrillogenesis. In addition, by decipher- 


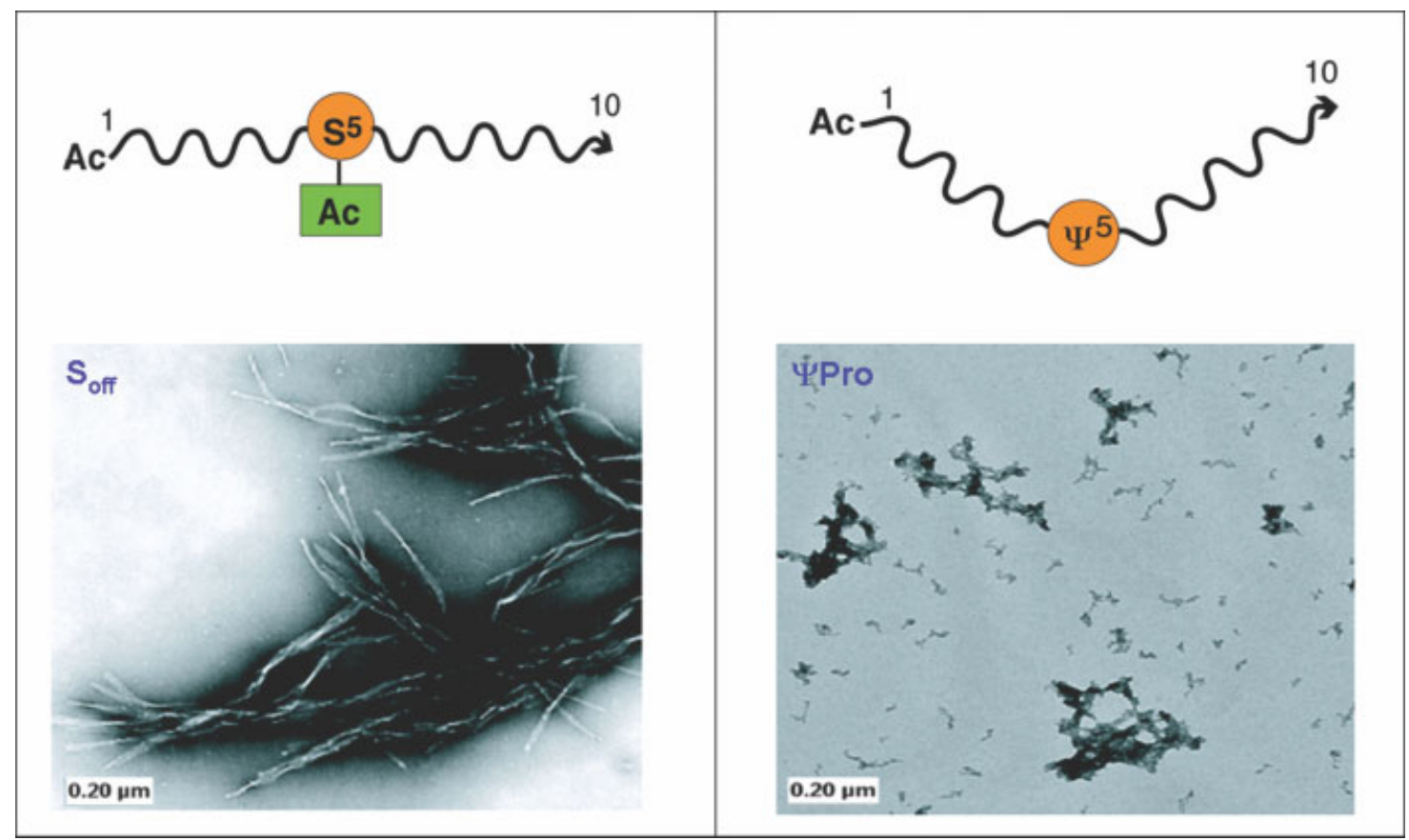

FIGURE 10 Comparison of the structure disrupting effect of $\mathrm{O}$-acyl isopeptide (left, $\mathrm{S}^{5}=\mathrm{N}$-acetyl protected Ser-derived depsipeptide bond) and $\Psi \operatorname{Pro}^{5}$ (right, $\Psi=$ Ser-derived C2-dimethyl

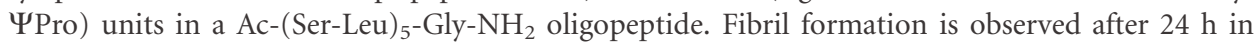
the depsipeptide bond containing folding precursor (left) while the presence of a kink conformation in the $\Psi \mathrm{Pro}^{5}$-peptide prevents the assembly of the peptide into fibrillar structures (right).

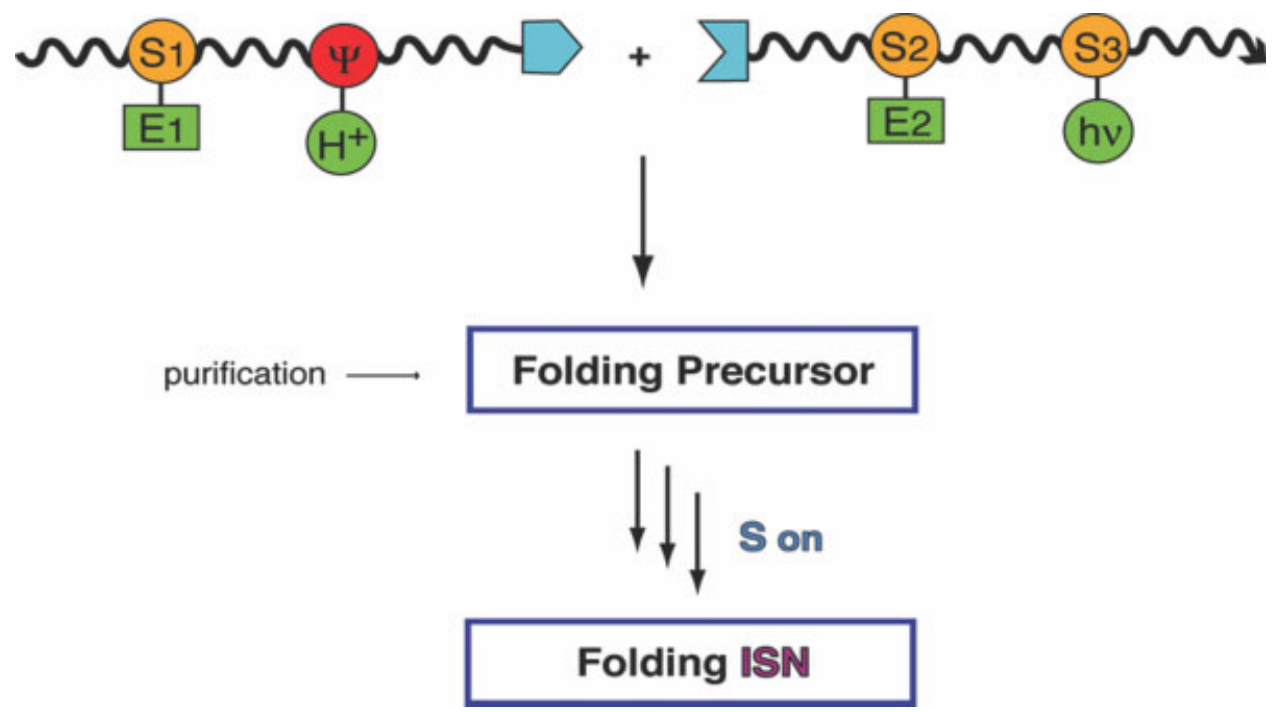

FIGURE 11 Switch-peptides as folding precursors for the convergent synthesis of polypeptides exhibiting high propensity for self-assembly and aggregation. In combining orthogonal triggering systems for $\mathrm{O}, \mathrm{N}$-acyl migration according to the switch concept (Figure 5), systems with structure disrupting $\Psi$ Pro building blocks in medium sized peptides, subsequent fragment condensation using chemoselective ligation techniques give access to folding precursors as powerful tools for the elucidation of the molecular origin of polypeptide self-assembly, misfolding, and fibrillogenensis. 
ing molecular key steps in early processes of fibrillogenesis related to degenerative diseases, the rational design of inhibitors of considerable therapeutic interest should be a most rewarding target.

\section{REFERENCES}

1. Mutter, M. Angew Chem Int Ed Engl 1985, 24, 639-652.

2. Tuchscherer, G.; Mutter, M. Chem Ind 1997, 15, 597-601.

3. Pillai, V. N. R.; Mutter M. Acc Chem Res 1981, 14, 122-130.

4. Toniolo, C.; Crisma, M.; Formaggio, F. Biopolymers 1996, 40, 627-651.

5. Creighton, T. E. Proteins, 2nd ed.; W. H. Freeman: New York, 1993.

6. Mutter, M.; Vuilleumier, S. Angew Chem Int Ed Engl 1989, 28, 535-554.

7. Mutter M.; Hersperger, R. Angew Chem Int Ed Engl 1990, 29, $185-187$.

8. Mutter, M.; Gassmann, R.; Buttkus, U.; Altmann, K.-H. Angew Chem Int Ed Engl 1991, 30, 1514-1516.

9. Aggeli, A.; Boden, N.; Zhang, S., Eds. Self-Assembling PeptideSystems in Biology, Medicine and Engineering; Kluwer: Dordrecht, 2001; and references therein.

10. Pagel, K.; Vagt, T.; Koksch, B. Org Biomol Chem 2005, 3, 3843 3850.

11. Lührs, T.; Ritter, C.; Adrian, M.; Riek-Loher, D.; Bohrmann, B.; Döbeli, H.; Schubert, D.; Riek, R. Proc Natl Acad Sci USA 2005, 102, 17342-17347.

12. Soto, C. Nat Rev Neurosci 2003, 4, 49-60.

13. Taylor, J. P.; Hardy, J.; Fischbeck, K. H. Science 2002, 296, 19911995.

14. Fowler, D. M.; Koulov, A. V.; Alory-Jost, C.; Marks, M. S.; Balch, W. E.; Kelly, J. W. PloS Biol 2006, 4, 100-107.

15. Lorenzo, A.; Yankner, B.A. Proc Natl Acad Sci USA 1994, 91, 12243-12247.

16. Kayed, R.; Head, E.; Thompson, J. L.; McIntire, T. M.; Milton, S. C.; Cotman, C. W.; Glabe, C. G. Science, 2003, 300, 486-489.

17. Fandrich, M.; Fletcher, M. A.; Dobson, C. M. Nature 2001, 410, 165-166.

18. Lansbury, P. T.; Lashuel, H. A. Nature, 2006, 443, 774-779.

19. Soto, C.; Estrada, L.; Castilla, J. Trends Biochem Sci 2006, 31, $150-155$.

20. Kapurniotu, A. In Self-Assembling Peptide-Systems in Biology, Medicine and Engineering; Aggeli, A.; Boden, N.; Zhang, S., Eds.; Kluwer: Dordrecht, 2001; Chapter 13.

21. Mihara, H.; Takahashi, Y.; Obataya, I.; Sakamoto, S. In SelfAssembling Peptide-Systems in Biology, Medicine and Engineering; Aggeli, A.; Boden, N.; Zhang, S., Eds.; Kluwer: Dordrecht, 2001; Chapter 14.

22. Jager, M.; Nguyen, H.; Crane, J. C.; Kelly, J. W.; Gruebele, M. J Mol Biol 2001, 311, 373-393.

23. Toniolo, C.; Bonora, G. M.; Mutter, M. J Am Chem Soc 1979, 101, 450-454.

24. Coltart, D. M. Tetrahedron 2000, 56, 3449-3491.

25. Shao, Y.; Paulus, H. J Peptide Res 1997, 50, 193-198.

26. Giriat, I.; Muir, T. W. J Am Chem Soc 2003, 125, 7180-7181.

27. Hurley, T. R.; Colson, C. E.; Hicks, G.; Ryan, M. J. J Med Chem 1993, 36, 1496-1498.
28. Carpino, L. A.; Krause, E.; Sferdean, C. D.; Schühmann, M.; Fabian, H.; Bienert, M.; Beyermann, M. Tetrahedron Lett 2004, 45, 7519-7523.

29. Sohma, Y.; Sasaki, M.; Hayashi, Y.; Kimura, T.; Kiso, Y. Chem Commun 2004, 124-125.

30. Sohma, Y.; Sasaki, M.; Hayashi, Y.; Kimura, T.; Kiso, Y. Tetrahedron Lett 2004, 45, 5965-5968.

31. Hamada, Y.; Ohtake, J.; Sohma, Y.; Kimura, T.; Hayashi, Y.; Kiso, Y. Biorg Med Chem 2002, 10, 4155-4167.

32. Oliyai, R.; Stella, V. J. Bioorg Med Chem Lett 1995, 5, 27352740.

33. Wieslaw, M.; Kazmierski, W. M.; Bevans, P.; Furfine, E.; Spaltenstein, A.; Yang, H. Bioorg Med Chem Lett 2003, 13, 25232526.

34. Kiso, Y.; Matsumoto, H.; Yamaguchi, S.; Kimura, T. Lett Pept Sci 1999, 6, 275-281.

35. Hamada, Y.; Matsumoto, H.; Yamaguchi, S.; Kimura, T.; Hayashi, Y.; Kiso, Y. Bioorg Med Chem 2004, 12, 159-170.

36. Skwarczynski, M.; Sohma, Y.; Moguchi, M.; Kimura, T.; Hayashi, Y.; Kiso, Y. J Org Chem 2006, 71, 2542-2545.

37. Tam, J. P.; Xu, J.; Eom, K. D. Biopolymers (Pept Sci) 2001, 60, 194-205.

38. Dawson, P. E.; Kent, S. B. H. Annu Rev Biochem 2000, 69, $923-$ 960.

39. Kent, S. B. H. J Pept Sci 2003, 9, 574-593.

40. Mutter, M.; Chandravarkar, A.; Boyat, C.; Lopez, J.; Dos Santos, S.; Mandal, B.; Mimna, R.; Murat, K.; Patiny, L.; Saucède, L.; Tuchscherer, G. Angew Chem Int Ed Engl 2004, 43, 4172-4178.

41. Dos Santos, S.; Chandravarkar, A.; Mandal, B.; Mimna, R.; Murat, K.; Saucède, L.; Tella, P.; Tuchscherer, G.; Mutter, M. J Am Chem Soc 2005, 127, 11888-11889.

42. Saucède, L.; Dos Santos, S.; Chandravarkar, A.; Mandal, B.; Mimna, R.; Murat, K.; Camus, M.-S.; Bérard, J.; Grouzmann, E.; Adrain, M.; Dubochet, J.; Lopez, J.; Lashuel, H.; Tuchscherer, G.; Mutter, M. Chimia 2006, 60, 199-202.

43. Sohma, Y.; Kiso, Y. ChemBioChem 2006, 7, 1549-1557.

44. Coin, I.; Dölling, R.; Krause, E.; Bienert, M.; Beyermann, M.; Sferdean C. D.; Carpino, L. A. J Org Chem 2006, 71, 6171-6177.

45. Merrifield, R. B. J Am Chem Soc 1963, 85, 2149-2154.

46. Mimna, R.; Mutter, M. Int J Pept Res Ther, in press.

47. Beck-Sickinger, A.; Jung, G. Biopolymers (Pept Sci) 1995, 37, 123-142.

48. Malis, D.-D.; Grouzmann, E.; Morel, D. R.; Mutter, M.; Lacroix, J.-S. Br J Pharmacol 1999, 126, 1-8.

49. Pagel, K.; Wagner, S. C.; Samedow, K.; von Berlepsch, H.; Böttcher, C.; Koksch, B. J Am Chem Soc 2006, 128, 2196-2197.

50. Ambroggio, X. I.; Kuhlman, B. J Am Chem Soc 2006, 128, 1154-1161.

51. Carulla, N.; Caddy, G. L.; Hall, D. R.; Zurdo, J.; Gairi, M.; Felliz, M.; Giralt, E.; Robinson, C. V.; Dobson, C. M. Nature 2005, 436, 554-558.

52. Mimna, R.; Camus, M.-S.; Schmid, A.; Tuchscherer, G.; Lashuel, H. A.; Mutter, M. Angew Chem Int Engl, in press.

53. Shepherd, N. E.; Abbenante, G.; Fairlie, D. P. Angew Chem Int Ed Engl 2004, 43, 2687-2690.

54. Abd El Rahman, S.; Anzinger, H.; Mutter, M. Biopolymers 1980, 19, 173-187.

55. Toniolo, C.; Bonora, G. M.; Mutter, M.; Pillai, V. N. R. Makromol Chem 1981, 182, 1997-2005. 
56. Toniolo, C.; Bonora, G. M.; Mutter, M.; Pillai, V. N. R. Makromol Chem 1981, 182, 2007-2014.

57. Mutter, M.; Altmann, K. H.; Bellof, D.; Floersheimer, A.; Herbert, J.; Huber, M.; Klein, B.; Strauch, L.; Vorherr, T.; Gremlich, H. U.In Proceedings of Ninth American Peptide Symposium, 1985, 397-405.

58. Kent, S. B. H. Annu Rev Biochem 1988, 57, 957-989.

59. Haack, T.; Mutter, M. Tetrahedron Lett 1992, 33, 1589-1592.

60. Wöhr, T.; Wahl, F.; Nefzi, A.; Rohwedder, B.; Sato, T.; Sun, X.; Mutter, M. J Am Chem Soc 1996, 118, 9218-9227.

61. Mutter, M.; Nefzi, A.; Sato, T.; Sun, X.; Wahl, F.; Wöhr, T. Pept Res 1995, 8, 145-153.
62. Moroder, L.; Renner, C.; Lopez, J. J.; Mutter, M.; Tuchscherer, G. In cis-trans Isomerization in Biochemistry; Dugave, C., Ed.; Wiley-VCH: Weinheim, 2006; Chapter 11.

63. Goodman, M., Ed. in Chief. Houben-Weyl. Methods of Organic Synthesis, Vol. E22d: Synthesis of Peptides and Peptidomimetics; Felix, A.; Moroder, L.; Toniolo, C., Eds.; Thieme Stuttgart: New York, 2003.

64. Muir, T. W.; Sondhi, D.; Cole, P. A. Proc Natl Acad Sci USA 1998, 95, 6705-6710.

65. Machova, Z.; von Eggelkraut-Gottanka, R.; Wehofsky, N.; Bordusa, F.; Beck-Sickinger, A. Angew Chem Int Ed Engl 2003, 42, $4916-4918$ 